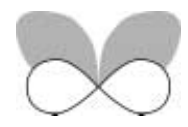

\title{
Phytogeography of upwelling areas in the Arabian Sea
}

Tom Schils* and Eric Coppejans Phycology Research Group, Biology Department, Ghent University, Krijgslaan, Ghent, Belgium

\begin{abstract}
Aim The identification of the marine plant communities of two islands from different upwelling areas of the Arabian Sea, with a similar diversity in biotopes. A comparison of the species composition of these macroalgal communities and their biogeographical affinities within the Indian Ocean should give insight into the biogeographical position of the Arabian Sea within the larger Indian Ocean. The incorporation of environmental parameters in the analysis is instructive in understanding their importance in shaping the diverse marine assemblages of the Arabian Sea.
\end{abstract}

Location Arabian Sea: (1) the Socotra Archipelago (Yemen; $12.47^{\circ} \mathrm{N}, 53.87^{\circ} \mathrm{E}$ ) in the Somali upwelling area, (2) Masirah Island (Oman; $20.42^{\circ} \mathrm{N}, 58.79^{\circ} \mathrm{E}$ ) in the upwelling area of the southern Arabian Peninsula.

Methods The marine flora of different biotopes around both islands were examined by means of qualitative assessments. Ordination analysis [detrended correspondence analysis (DCA)] was used to identify the different plant communities and to correlate these with environmental parameters. The species composition of the identified communities were compared (tripartite similarity index) and their biogeographical affinity with nations bordering the Indian Ocean was determined. Indicator species analyses were performed to identify the characteristic species of the different plant communities and their biotopes.

Results The DCA analysis shows a clustering of sites (plant communities) corresponding with their geographical position, linked in turn to the prevailing environmental conditions of the different coastal areas. The combined interpretation of the ordination, similarity and biogeographical analyses results in the aggregation of similar plant communities of both upwelling areas into four biotopes.

Main conclusions The north coast communities of Socotra and the west coast communities of Masirah can be grouped into three biotopes related to the degree of exposure (to upwelling) and sedimentation. These biotopes are typified by indicator species, characteristic for specific substrata, and have a high biogeographical affinity with the East African coast. The plant communities of Socotra's south coast and Masirah's east coast constitute a fourth biotope, being diverse and species rich, typified by a large proportion of red macroalgae including the characteristic species of the unique Arabian Sea flora. This biotope has a pronounced biogeographical affinity with distant regions (disjunctly distributed taxa) as South Africa's East Coast and Western Australia. Within the different biotopes, the communities of Masirah are more divergent from an East African flora in comparison to Socotra, the latter being a stepping stone between the East African and Arabian Sea flora.

\section{Keywords}

Arabian Sea, biogeography, ecology, macroalgae, Masirah Island, northern Indian Ocean, seagrass, seaweed, Socotra Archipelago.

\footnotetext{
"Correspondence: Tom Schils, Phycology Research Group, Biology Department, Ghent University, Krijgslaan 281 (S8), 9000 Ghent, Belgium.

E-mail: tom.schils@ugent.be
} 


\section{INTRODUCTION}

The Arabian Sea is regarded as a biogeographical subregion of the Indian Ocean (Sheppard et al., 1992). Seasonal upwelling, maximal in strength during the south-west monsoon (summer), influences the greater part of the Arabian Sea coasts and is considered as the main regulating phenomenon for a biogeographical barrier in the area (Wilson, 2000).

Case studies on the macroalgae of confined areas within the Arabian Sea (Wynne \& Banaimoon, 1990; Ormond \& Banaimoon, 1994; Wynne \& Jupp, 1998; Schils, 1999; Wynne, 1999a,b, 2000, 2001; Leliaert, 2000; Wynne \& Leliaert, 2001; Schils, 2002; Schils \& Coppejans, 2002; Schils et al., 2003a,b) indicate that the region harbours a species rich and diverse marine flora. The upwelling area along the Hadramout (Yemen) and Dhofar (Oman) coasts on the southern Arabian Peninsula is a centre of high endemism within the Arabian Sea (Sheppard \& Salm, 1988; Randall \& Hoover, 1995). Within this area, Masirah Island has been comparatively well investigated as the island harbours a wide diversity of biotopes (from upwelling affected shores to large monotypic reefs) within a limited geographical area (de Vaugelas, 2001). The Socotra Archipelago, located within the Somali upwelling area, is likewise identified as the 'Galapagos of the Indian Ocean' (Wilson \& Klaus, 2000) because of its diversity in biota and biotopes. The archipelago recently received scientific interest owing to the comparatively pristine state of its natural environment. The marine ecosystems of Socotra also vary from coral dominated communities to upwelling influenced shores, with clearly defined subtidal plant communities (Schils \& Coppejans, 2003). The Socotra Archipelago is located at the boundary of many species distributions (sympatry of sister taxa; Kemp, 1998b) and it serves as a stepping stone for genetic exchange, by means of larval and spore dispersal, between the Indian Ocean, the Red Sea (Gulf of Aden) and the Arabian Sea. Besides being located on the crossroads of these biogeographical regions, the Arabian Sea flora shows pronounced biogeographical affinities with distant marine floras (Børgesen, 1934; Wynne, 2000; Schils \& Coppejans, 2002; Schils et al., 2003a). Despite these anecdotic observations, no quantitative research has been performed in order to characterize the different plant communities of the Arabian Sea and to determine their similarity, diversity and biogeography. This study attempts to provide insight into the diversity and unicity of the region by comparing detailed species inventories of different sampling sites within the Somali and southern Arabian upwelling areas. Biomass analyses of vegetation quadrats around the Socotra Archipelago (Schils \& Coppejans, 2003) showed that a qualitative comparison (presence/absence of taxon data) returns reliable results if the sites are intensively sampled in a relatively wide vertical (different zones) and horizontal range (large sample area).

\section{MATERIALS AND METHODS}

The field trips to Masirah Island and the Socotra Archipelago were conducted by the first author in the period between two successive SW monsoons, from 2 to 30 November 1999 and from 26 March to 7 May 2000, respectively. During the qualitative surveys, samples were collected from intertidal and subtidal habitats to $20 \mathrm{~m}$ depth. Plants were gathered in fine-meshed plastic bags and sorted in a field laboratory. Small and crustose algae were excluded from the data set as they can easily be overlooked from one survey to another and a meticulous investigation of the whole substratum and epiphytes is very time-consuming. Reference specimens were selected and pressed as herbarium specimens, preserved in a $5 \%$ formaldehyde-seawater solution or dried in silica gel for molecular purposes. This collection is housed in GENT (Ghent University Herbarium, Krijgslaan 281-S8, 9000 Ghent, Belgium).

\section{Ordination}

The forty-eight sample sites (Fig. 1) of which complete species inventories were recorded (1048 species records) served as the ordination input. Detrended correspondence analysis (DCA performed with CANOCO; ter Braak, 1988) was chosen as an indirect gradient analysis as the data clearly represent a unimodal model (maximum gradient length: 5.227 SD; ter Braak \& Šmilauer, 1998).

In an attempt to determine the species-environment correlation, environmental data around Socotra (latitude: 9.650-14.383 ${ }^{\circ} \mathrm{N}$; longitude: $\left.51.900-57.067^{\circ} \mathrm{E}\right)$ and Masirah (latitude: 18.080-22.500 $\mathrm{N}$; longitude: 57.850$\left.61.950^{\circ} \mathrm{E}\right)$ were obtained from the Worldwide Ocean Optics Database (http://wood.jhuapl.edu, WOOD version 4.0). Chlorophyll a (CHL), salinity (SAL) and temperature (TMP) parameters (1) showed a good sample distribution and (2) were sampled during the SW monsoon (Julian days 121-304; abbreviated as 'parameter' + '_SW') and the NE monsoon (Julian days 305-120; 'parameter' + '_NE') for both islands. The average of these parameters during one of the monsoons was calculated for two geographical areas (water masses) around the islands: (1) Socotra's north coast, $>12.550^{\circ} \mathrm{N}$; (2) Socotra's south coast, $<12.550^{\circ} \mathrm{N}$; (3) Masirah's west coast, $<58.637^{\circ} \mathrm{E}$; (4) Masirah's east coast, $>58.637^{\circ}$ E. The south coast of Socotra and the east coast of Masirah are the main upwelling areas of the islands. Socotra's north coast and Masirah's west coast are on the lee side of the major current patterns and less influenced by the upwelling phenomenon. Whereas SAL and TMP are directly related to upwelling and are influential for algal growth, CHL represents the overall productivity of the phytoplankton, linked to the changes in dissolved nutrients and hence is indirectly related to upwelling. Additional parameters were derived from the original data, i.e. the absolute difference of a parameter between the two monsoon periods (abbreviation of the environmental parameter + '_AD') and the average of both monsoon periods (parameter + 'AV'). The complete environmental data set had identical parameter values for all sites of a specific area. 
Figure I Map of the Arabian Sea (a) with Masirah Island (b) and the Socotra Archipelago (c) as insets. The sample sites are indicated according to their clustering in the DCA plot: east coast of Masirah (MAS EC, open circles), seagrass beds of Masirah (MAS SG, open boxes), west coast of Masirah (MAS WC, open triangles), north coast of Socotra and two sheltered sites in Mahfirhin Bay (SOC NC, asterisks), north coast of Socotra and outer islands (S\&O NC, filled triangles), seagrass beds of Socotra (SOC SG, filled box) and south coast of Socotra and outer islands (S\&O SC, filled circles). The scale bar represents $1000 \mathrm{~km} \mathrm{(a),} 25 \mathrm{~km}$ (b) and $50 \mathrm{~km}(\mathrm{c})$, respectively.

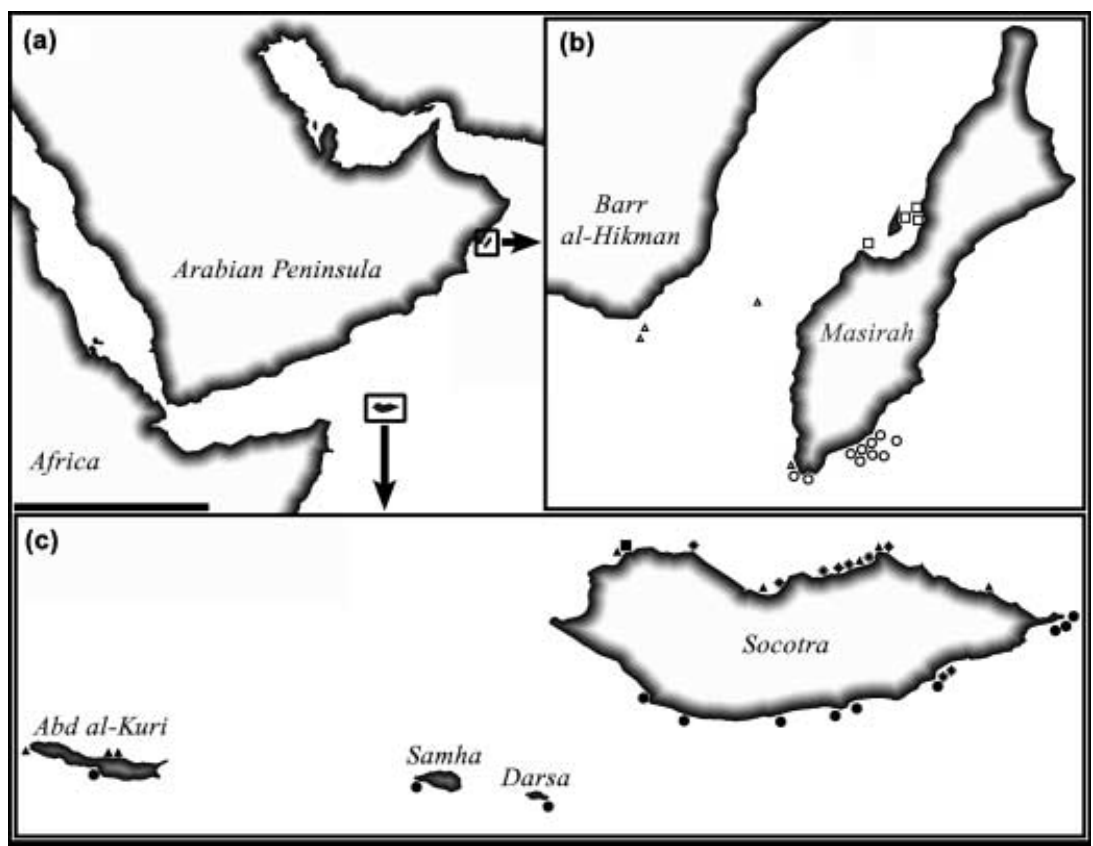

\section{Indicator analysis}

Indicator species analysis was used to examine the characteristic species, showing significant indicator values (IV), for each of the marine plant communities (DCA clusters) and biotopes (grouping of similar communities of Socotra and Masirah). The indicator analyses were conducted with PC-ORD (McCune \& Mefford, 1999), using 1000 Monte Carlo random permutations to test the statistical significance of the indicator values.

\section{Species richness and similarity}

Subsequent analyses of the plant communities included the calculation of species richness (specified per Phylum/Class) for each DCA cluster, and the tripartite similarity index (Tulloss, 1997) as a qualitative index of beta diversity.

\section{Biogeography affinity analysis}

The biogeographical affinity of the plant communities are analysed by comparing the species composition of the DCA clusters to species inventories of Indian Ocean nations. The latter data set is primarily based on Silva et al. (1996) and supplemented with records from omitted and recent sources: Dickie (1888), Holmes (1903), Nizamuddin \& Campbell (1995), De Clerck \& Coppejans (1996, 1999), Critchley et al. (1997), Kemp (1998a), Wynne \& Jupp (1998), cd-rom 'Mangroves and seagrasses of the Indian Ocean' (R. Phillips and M. Spalding; Indian Ocean Guides, Department of Biological Sciences, University of Warwick, 1998), De Clerck (2003); Wynne (1999a,b, 2000, 2001), Coppejans et al. (2000), Huisman (2000), Wynne \&
Leliaert (2001), De Clerck et al. (2002). The floristic affinity of a cluster with a specific country is calculated as the Simpson coefficient: $a(a+\min (b, c))^{-1} \times 100$, where $a$ represents the number of shared species between a cluster and a country, $b$ and $c$ represent the number of species unique to the cluster and the country, respectively. The species inventories of the clusters are always smaller than those of the countries, so the equation does not include the floristic richness of a country which reduces the discrepancy of sampling efforts between the different countries. The countries are arranged from south-eastern Africa, over the Arabian Sea, to Western Australia. India was excluded from the series as its size and geographical position cover a wide diversity of floras within the Indian Ocean. In order to visualize the main biogeographical trends of the site clusters, based on both species and generic inventories, the plots are best represented as polynomial trend lines of a fourth order.

\section{RESULTS}

\section{Species account}

A total of 236 plant species were recorded for the forty-eight sites (Appendix 1): six seagrasses (Magnoliophyta), fiftythree Chlorophyta, forty-three Phaeophyta and 134 Rhodophyta. Certain species of the same genus with a similar ecology could not be discerned in the field, therefore the 236 taxa are lumped into 204 species abbreviations (Appendix 1 ), which are used in the subsequent analyses. The number of recorded genera totals 128: five seagrasses (Magnoliophyta), twenty-six Chlorophyta, seventeen Phaeophyta and eighty Rhodophyta. 


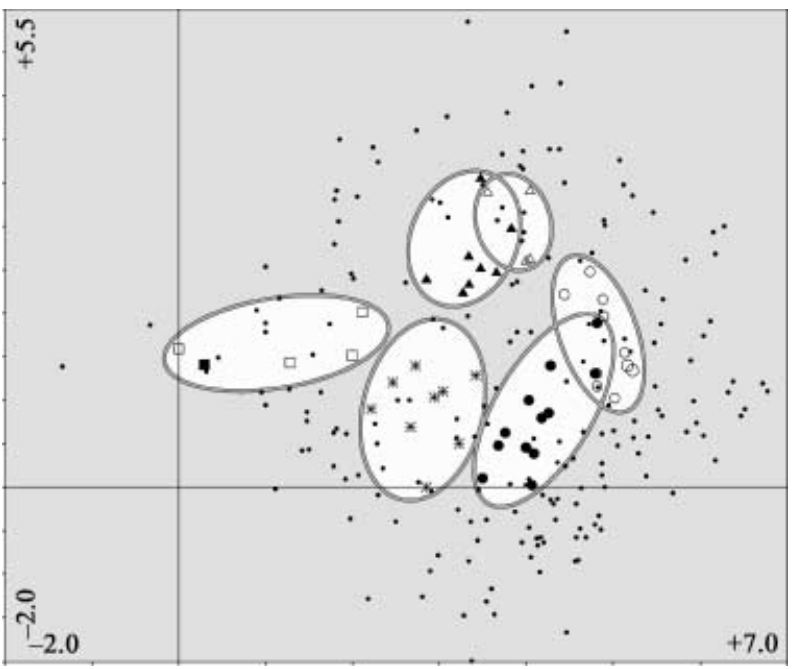

Figure 2 First two ordination axes of a DCA based on the qualitative site data (species records, represented as small dots). The six DCA clusters indicative for the different plant communities are encircled. Sample site symbols as in Fig. 1.

\section{Ordination}

A DCA of the species data of the forty-eight sites showed six site groupings (Fig. 2), corresponding with coastal areas around both islands. Both axes have high eigenvalues $(0.525$ and 0.406) and high lengths of gradient (5.226 and 3.531), indicating a high beta diversity within the samples. The six DCA clusters are identified as (Fig. 2, counter clockwise starting from the left): (1) the seagrass beds of Socotra (SOC SG) and Masirah (MAS SG); (2) a distinct entity of Socotra's north coast sites (SOC NC); (3) the south coast sites of Socotra and the outer islands (Abd al-Kuri, Samha, Darsa; S\&O SC); (4) the east coast of Masirah (MAS EC); (5) the west coast sites of Masirah (MAS WC); and (6) the north coast sites of Socotra and the outer islands (S\&O NC). Figure 3 shows the proportion of seagrasses, Rhodophyta, Phaeophyta and Chlorophyta in the total number of species and genera recorded for each cluster. The DCA plot of the first two axes shows an overlap in sites belonging to $\mathrm{S} \& \mathrm{O}$ NC and MAS WC; and a partial overlap between S\&O SC and MAS EC.

Table 1 lists the correlation coefficients of the environmental parameters with the first two DCA axes. The salinity parameters SAL_AD, SAL_AV and SAL_NE have the highest correlation values with the first DCA axis (the latter two being negatively correlated) and lower ones with the second axis (all negatively correlated). The average TMP and the CHL concentrations show a highly significant $(P<0.01)$ correlation with both DCA axes. As these parameters are positively correlated with both axes, they represent the difference in environmental variables between the Socotra clusters and the Masirah clusters, which are plotted in the upper right-hand corner of the DCA, following the resultant of both axes. High CHL concentrations (a)

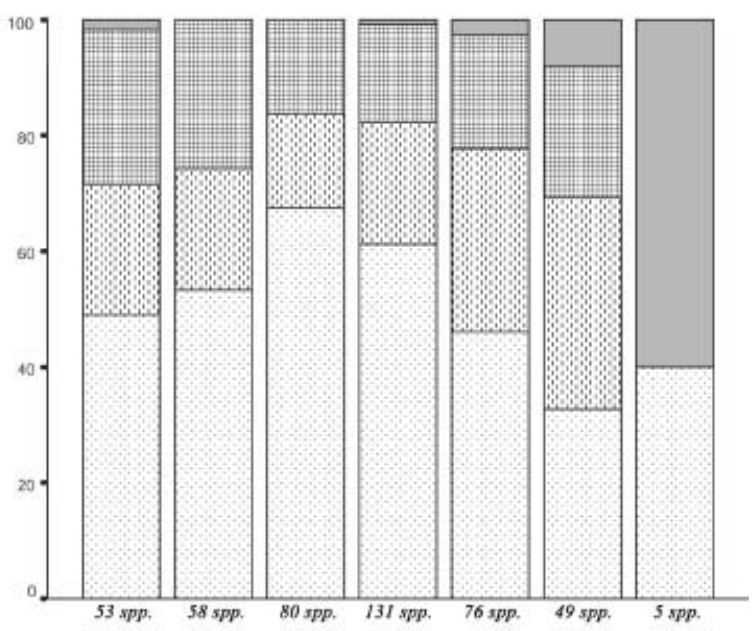

(b)

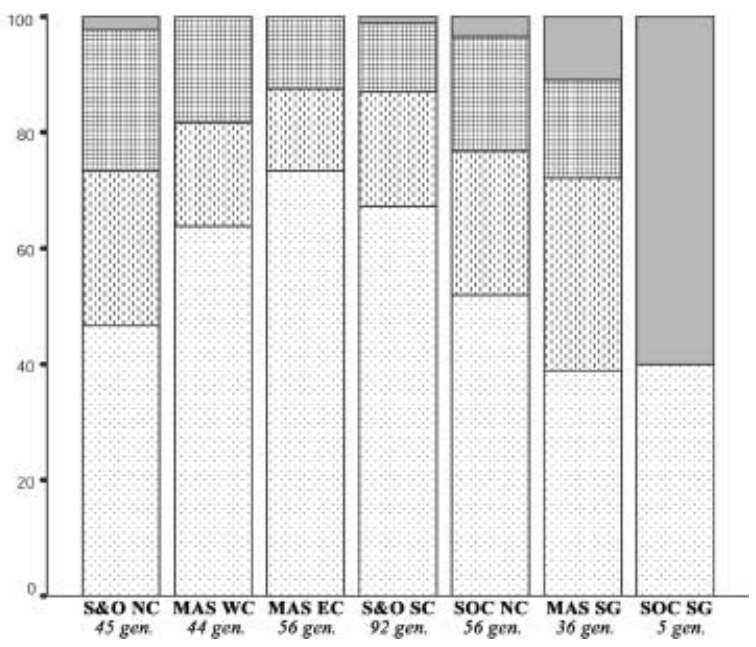

Figure 3 Percentage of Rhodophyta (dotted), Chlorophyta (vertical stripes), Phaeophyta (hatched) and seagrasses (grey shaded) in the total account of genera and species for each DCA cluster. Cluster abbreviations as in Fig. 1. (a) Number of species per cluster. (b) Number of genera per cluster.

are indicative of upwelling, the effect of this phenomenon thus being stronger at Masirah in comparison with Socotra. The average CHL concentration at Masirah $\left(1.55 \mu \mathrm{g} \mathrm{L}^{-1}\right)$ is almost four times as high compared with that of the Socotra clusters $\left(0.40 \mu \mathrm{g} \mathrm{L}^{-1}\right)$. Similarly, TMP_AV differs between Socotra and Masirah. The average yearly TMP turns out to be higher around Masirah Island $\left(24.9^{\circ} \mathrm{C}\right)$ in comparison with the Socotra Archipelago $\left(24.5^{\circ} \mathrm{C}\right)$ because of the higher winter temperatures of the upwelling sheltered sites $\left(26.1^{\circ} \mathrm{C}\right.$ vs. $\left.24.9^{\circ} \mathrm{C}\right)$. The remaining TMP parameters (TMP_NE, TMP_AD, TMP_SW) and SAL_SW have low correlation coefficients (not significant, $P<0.01$ ) with both axes, pointing out the slight differences of the seasonal temperature between both islands, the small differences in temperature changes between both monsoon periods, and the similar salinities for both islands during the SW monsoon. 
Table I Correlation coefficients of the twelve environmental parameters in decreasing order (absolute values) with the first two axes of the DCA, respectively. Abbreviations of parameters as in text

\begin{tabular}{lcc}
\hline Parameter & Axis 1 & Axis 2 \\
\hline SAL_AD & $0.689^{*}$ & -0.239 \\
SAL_AV & $-0.588^{*}$ & -0.284 \\
SAL_NE & $-0.470^{*}$ & -0.277 \\
TMP_AV & $0.453^{*}$ & $0.306^{*}$ \\
CHL_SW & $0.402^{*}$ & $0.428^{*}$ \\
CHL_AD & $0.397^{*}$ & $0.402^{*}$ \\
CHL_AV & $0.397^{*}$ & $0.427^{*}$ \\
CHL_NE & $0.384^{*}$ & $0.420^{*}$ \\
TMP_NE & 0.241 & 0.042 \\
TMP_AD & 0.118 & -0.072 \\
TMP_SW & 0.076 & 0.226 \\
SAL_SW & 0.066 & 0.030 \\
----------------------------------------------------- & $0.428^{*}$ \\
CHL_SW & $0.402^{*}$ & $0.427^{*}$ \\
CHL_AV & $0.397^{*}$ & $0.420^{*}$ \\
CHL_NE & $0.384^{*}$ & $0.402^{*}$ \\
CHL_AD & $0.397^{*}$ & $0.306^{*}$ \\
TMP_AV & $0.453^{*}$ & -0.284 \\
SAL_AV & $-0.588^{*}$ & -0.277 \\
SAL_NE & $-0.470^{*}$ & -0.239 \\
SAL_AD & $0.689^{*}$ & 0.226 \\
TMP_SW & 0.076 & -0.072 \\
TMP_AD & 0.118 & 0.042 \\
TMP_NE & 0.241 & 0.030 \\
SAL_SW & 0.066 & \\
\hline
\end{tabular}

*High significant parameters $(P<0.01)$.

\section{Tripartite similarity}

The tripartite similarity indices are shown in Table 2, in which the sites are ordered so that the highest indices adjoin the diagonal. This results in a linear representation of sites that are most similar to one another. MAS WC and MAS EC have the highest similarity index with one another $(0.51)$, but the former also has a high similarity index with $\mathrm{S} \& \mathrm{O}$ NC (0.48) and the latter with S\&O SC (0.47). S\&O SC has equal similarity indices for MAS EC and SOC NC. MAS SG has the highest index with SOC NC (0.47). All similarity indices with SOC SG are very low because of the low species richness of this cluster. SOC SG has its highest similarity index with MAS SG (0.08).

\section{Biogeography affinity analysis}

SOC SG was omitted from the analysis, as this site only contained five species. The dominant factors that determine species occurrence at SOC SG are the harsh and variable ecological conditions characteristic of lagoons, as opposed to the biogeographical distribution patterns of species.

The biogeographical trends of the DCA clusters based on the species inventories (Fig. 4a) shows a decreasing affinity with the Indian Ocean from the seagrass beds to the upwelling zones: MAS SG $(47.8 \%)>$ S\&O NC $(46.5 \%)>$ MAS WC $(42.6 \%)>$ SOC NC $(40.2 \%)>$ S\&O SC $(33.6 \%)$, MAS EC $(33.5 \%)$. In general, the biogeographical affinities increase from South Africa to Kenya, decrease from Somalia to Malaysia and increase again towards Indonesia and Western Australia.

In addition to the biogeographical comparison based on species lists, affinities at a generic level were also calculated (Fig. 4b) as certain Indian Ocean taxa have been identified by a plethora of names (to some extent corrected for in the analyses) dependent on the author or the phycological school. The identifications at genus level, however, are more rigid. The generic affinities of the clusters with the Indian Ocean nations are markedly higher than those based on the species lists. The decreasing order of general affinity with the Indian Ocean are similar to the results of the species analysis: highest affinity for MAS SG (77.4\%); high affinities for SOC NC $(74.7 \%)$, S\&O NC (73.3\%) and MAS WC (71.4\%); and lower affinities for MAS EC (58.3\%) and S\&O SC $(57.4 \%)$.

All clusters have high affinities with both ends of the graphs (Fig. 4a,b), corresponding with South Africa and Western Australia, respectively. Parts of these nations are subjected to temperate waters and other parts to (sub)tropical waters, resulting in high affinities with all plant communities of the Arabian Sea defined here. The overall biogeographical affinities are highest with the East African coast and surprisingly lower with the Arabian Sea. The affinities of the SOC $(\mathrm{S} \& \mathrm{O})$ and MAS communities with Yemen and Oman, respectively, are by definition $100 \%$. This result is, however, not obtained from the analysis because the species lists of the Indian Ocean nations are based on literature reports. Consequently, many of the species reported here are new records for Yemen and Oman.

In both biogeographical analyses, Sri Lanka is an outlier (Fig. 4a,b). To date, no other reports of strong affinities
Table 2 Tripartite similarity indices of DCA cluster couples. Clusters are ordered in a way that their highest similarities adjoin the diagonal position. Similarities $>0.40$ are marked in bold. Cluster abbreviations as in Fig. 1

\begin{tabular}{llllllll}
\hline & S\&O NC & MAS WC & MAS EC & S\&O SC & SOC NC & MAS SG & SOC SG \\
\hline S\&O NC & - & 0.48 & 0.40 & 0.34 & 0.38 & 0.36 & 0.03 \\
MAS WC & $\mathbf{0 . 4 8}$ & - & $\mathbf{0 . 5 1}$ & 0.31 & 0.28 & 0.34 & 0.02 \\
MAS EC & 0.40 & $\mathbf{0 . 5 1}$ & - & 0.47 & 0.35 & 0.17 & 0.02 \\
S\&O SC & 0.34 & 0.31 & $\mathbf{0 . 4 7}$ & - & 0.47 & 0.20 & 0.02 \\
SOC NC & 0.38 & 0.28 & 0.35 & 0.47 & - & 0.39 & 0.04 \\
MAS SG & 0.36 & 0.34 & 0.17 & 0.20 & 0.39 & - & 0.08 \\
SOC SG & 0.03 & 0.02 & 0.02 & 0.02 & 0.04 & 0.08 & - \\
\hline
\end{tabular}


(a) 100

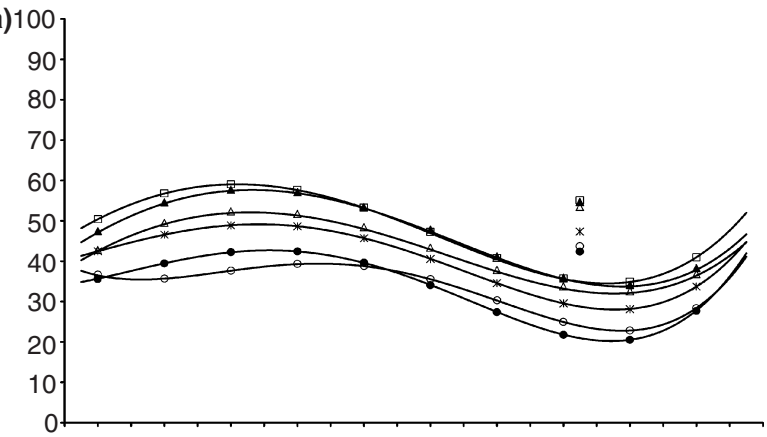

(b) 100

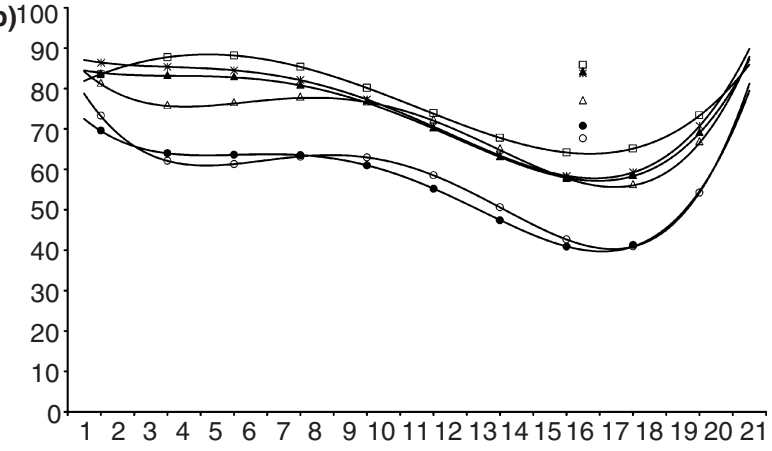

Figure 4 Biogeographical affinities (Simpson coefficient in \%, $y$-axis) between the species lists of the DCA clusters and those of the Indian Ocean nations. The countries are ordered on the $x$-axis from the south-western Indian Ocean, over the Arabian Sea, to the southeastern Indian Ocean: South Africa (1), Mozambique (2), Madagascar (3), Réunion (4), Mauritius (5), Tanzania (6), Seychelles (7), Kenya (8), Somalia (9), Yemen (10), Oman (11), Iran (12), Pakistan (13), Laccadive (14), Maldives (15), Sri Lanka (16), Bangladesh (17), Andaman (18), Malaysia (19), Indonesia (20), Australia (21). DCA cluster symbols as in Fig. 1: MAS WC (open triangles), MAS SG (open boxes), MAS EC (open circles), S\&O NC (filled triangles), SOC NC (stars), and S\&O SC (filled circles). (a) Quartic polynomial trend lines of the biogeographical affinity of the DCA clusters based on the species records. (b) Quartic polynomial trend lines of the biogeographical affinity of the DCA clusters based on the generic records. The biogeographical affinities of Sri Lanka behave as outliers for all polynomial trend lines, hence their separate representation in both graphs.

between the marine communities of the Arabian Sea and Sri Lanka are known. Being on the crossroads of the Arabian Sea, the Bay of Bengal and the Indian Ocean, the high similarities can be attributed to common Indian Ocean taxa that also occur in the tropical regions of the East African coast (e.g. Kenya and Tanzania). Calculations support this statement: out of the eighty-three species that the Arabian Sea (ordination data) and Sri Lanka share, seventy-six and seventy-three species have also been reported for Kenya and Tanzania, respectively. Of the eighty-five genera found in the Arabian Sea and Sri Lanka, eighty and eighty-three genera are also known for Kenya and Tanzania, respectively.

\section{Indicator species}

The species, with a significant indicator value $(P<0.05)$, listed in Table 3 prove to be characteristic for the identified DCA clusters. S\&O NC contains only three indicator species, being common Indian Ocean taxa. The indicator species of MAS WC are predominantly composed of Phaeophyta (six of nine). The indicator species Nizamuddinia zanardinii and Lomentaria strumosa are endemic for the Arabian Sea and ecologically associated with the upwelling phenomenon (Kemp, 1998a). The other large Phaeophyta (Dictyota bartayresiana, Sargassum spp., Stoechospermum polypodioides, Turbinaria ornata) are generally linked to increased nutrient levels in (sub)tropical seas (Schaffelke \& Klumpp, 1998). MAS EC is typified by indicator species predominantly belonging to the Rhodophyta. Many of these species are indicative of colder water, e.g. Calliblepharis fimbriata, Kallymenia crassiuscula, Plocamium telfairiae and Rhodymenia spp., and show a disjunct distribution pattern within the Indo-Pacific. Similar observations to those of MAS EC apply for the indicator species of S\&O SC. Despite the high number of species records for SOC NC, the majority of species found in this cluster also occur in other clusters. This results in only three species with significant indicator values, being common Indian Ocean species. The species-rich seagrass beds of MAS SG are characterized by plants typically associated with these habitats. SOC SG was excluded from the analysis because of its extremely low species richness.

In a second indicator species analysis, the plant communities of both islands (DCA clusters) are united in biotopes, based on similarities in species composition and biogeographical trends. This results in three clusters that are composed of Socotra and Masirah sites, and a single Socotra cluster. S\&O NC and MAS WC are united in a cluster composed of upwelling sheltered sites, S\&M SS. S\&O SC and MAS EC are combined in a cluster composed of upwelling affected sites, S\&M US. SOC SG and MAS SG are joined in the cluster of seagrass communities, S\&M SG. SOC NC shows the highest similarity in species composition with S\&O SC although its biogeographical affinity more closely resembles that of S\&O NC. Because of its mixed behaviour, SOC NC was retained from aggregation with other clusters. The sites of these cluster groupings correspond with the areas of both islands that are subject to similar seasonal environmental conditions. A subsequent species indicator analysis revealed the species that are characteristic for each of the four biotopes in the Arabian Sea (Table 4).

Nizamuddinia zanardinii and Sargassum linearifolium are indicator species of S\&M SS that make up the largest biomass stands of the studied macroalgal communities (excluding the seagrass communities; T. Schils, pers. obs.). Besides N. zanardinii, the indicator species of S\&M SS have a wide (sub)tropical distribution within the Indian Ocean. As a consequence of uniting S\&O SC and MAS EC, the indicator species of S\&M US are predominantly Rhodophyta, composing very diverse algal communities. Again, species indicative for colder water 
Table 3 Species with significant probabilities $(P<0.05)$ and indicator values (IV, percentage perfect indication) for each of the plant communities (DCA clusters). High indicator values are marked in bold and grouped according to cluster preference. Probabilities are based on 1000 Monte Carlo permutations. Cluster abbreviations as in Fig. 1. The species abbreviations correspond to the species listed in Appendix 1

\begin{tabular}{|c|c|c|c|c|c|c|c|}
\hline Species & $\mathrm{S} \& \mathrm{O} \mathrm{NC}$ & MAS WC & MAS EC & S\&O SC & SOC NC & MAS SG & $P$ \\
\hline Sar_lin & 38 & 0 & 0 & 0 & 0 & 0 & 0.027 \\
\hline Dic_fri & 37 & 0 & 1 & 1 & 0 & 0 & 0.008 \\
\hline Gel_pan & 25 & 0 & 0 & 0 & 0 & 0 & 0.039 \\
\hline Niz_zan & 2 & 64 & 0 & 0 & 0 & 0 & 0.002 \\
\hline Sar_sp1 & 0 & 56 & 0 & 0 & 0 & 6 & 0.002 \\
\hline Sto_pol & 3 & 52 & 5 & 0 & 1 & 3 & 0.004 \\
\hline Lom_stru & 0 & 50 & 0 & 0 & 0 & 0 & 0.010 \\
\hline Bry_spe & 1 & 49 & 1 & 2 & 0 & 0 & 0.003 \\
\hline Pte_cae & 15 & 38 & 2 & 4 & 2 & 2 & 0.017 \\
\hline Tur_orn & 2 & 35 & 0 & 1 & 0 & 0 & 0.030 \\
\hline Dic_bar & 0 & 35 & 1 & 0 & 2 & 0 & 0.035 \\
\hline Sar_pil & 0 & 33 & 0 & 0 & 0 & 8 & 0.039 \\
\hline Plo_tel & 0 & 21 & 41 & 0 & 0 & 0 & 0.018 \\
\hline Rho_sp2 & 0 & 0 & 70 & 0 & 0 & 0 & 0.001 \\
\hline Rho_sp1 & 0 & 7 & 52 & 0 & 0 & 0 & 0.001 \\
\hline Dic_cri & 0 & 6 & 44 & 2 & 0 & 0 & 0.006 \\
\hline Kal_spe & 0 & 0 & 43 & 1 & 0 & 0 & 0.011 \\
\hline Cal_fim & 0 & 0 & 40 & 0 & 0 & 0 & 0.007 \\
\hline Sci_tsi & 0 & 0 & 37 & 7 & 1 & 0 & 0.035 \\
\hline Gra_tex & 0 & 0 & 33 & 1 & 0 & 0 & 0.022 \\
\hline Amp_anc & 0 & 4 & 32 & 22 & 0 & 0 & 0.020 \\
\hline Hal_com & 0 & 0 & 0 & 67 & 0 & 0 & 0.001 \\
\hline Bot_lep & 0 & 0 & 0 & 50 & 0 & 0 & 0.012 \\
\hline Hal_dup & 0 & 0 & 0 & 50 & 0 & 0 & 0.005 \\
\hline Zel_spe & 0 & 0 & 0 & 42 & 0 & 0 & 0.007 \\
\hline Cry_spe & 0 & 0 & 0 & 33 & 2 & 0 & 0.012 \\
\hline Cha_ind & 0 & 0 & 0 & 33 & 0 & 0 & 0.049 \\
\hline Ast_pel & 3 & 0 & 0 & 32 & 0 & 0 & 0.021 \\
\hline Cau_lan & 0 & 0 & 0 & 3 & 64 & 0 & 0.002 \\
\hline Gra_deb & 0 & 0 & 2 & 0 & 47 & 0 & 0.006 \\
\hline Amp_fra & 5 & 0 & 0 & 8 & 44 & 0 & 0.010 \\
\hline Hal_uni & 0 & 0 & 0 & 0 & 1 & 90 & 0.001 \\
\hline Hal_ova & 0 & 0 & 0 & 0 & 0 & 75 & 0.001 \\
\hline Cho_pap & 0 & 0 & 0 & 0 & 1 & 65 & 0.004 \\
\hline Gra_sal & 0 & 0 & 0 & 0 & 0 & 50 & 0.014 \\
\hline Sar_fil & 0 & 0 & 0 & 0 & 2 & 41 & 0.023 \\
\hline Boe_for & 0 & 0 & 0 & 4 & 0 & 38 & 0.008 \\
\hline Cau_len & 0 & 0 & 0 & 1 & 2 & 36 & 0.032 \\
\hline Cau_sca & 0 & 0 & 0 & 1 & 2 & 36 & 0.028 \\
\hline
\end{tabular}

characterize this biotope, e.g. Kallymenia crassiuscula and Rhodymenia sp. 2. More indicator species were found for SOC NC in the second analysis, this however, being characteristic for similar habitats as those examined in the first analysis. The indicator species of S\&M SG are also identical with those of MAS SG in the previous species indicator analysis.

\section{DISCUSSION}

The plant communities defined in this study cover a larger geographical area compared with those derived from a biomass analysis of quadrat data around the Socotra Archipelago (Schils \& Coppejans, 2003). The transition zone between Socotra's south and north coast, and the outer island communities (both with a pronounced south coast affinity) are in the present study included in S\&O SC. The analysis of species inventories hence results in a substantial loss of resolution because the species structure (biomass data) of the different communities is excluded from the information input. However, in a comparison between the plant communities of different geographical locations (both islands), analogies among the communities of both islands can satisfactorily be assessed by a holistic approach incorporating analyses of site data (ordination), species data (similarity indices) and biogeographical distribution patterns.

The species composition of all clusters, excluding the seagrass communities (MAS SG and SOC SG), is proportionally dominated by red algae (number of species or genera per cluster). The Cheney ratio (the sum of the Rhodophyceae and Chlorophyceae divided by the number of Phaeophyceae; see Fig. 3) has been used in an attempt to link the floristic composition of macroalgal floras to their 


\begin{tabular}{|c|c|c|c|c|c|}
\hline Species & S\&M SS & S\&M US & SOC NC & S\&M SG & $P$ \\
\hline Pte_cae & 39 & 5 & 3 & 3 & 0.018 \\
\hline Niz_zan & 33 & 0 & 0 & 0 & 0.009 \\
\hline Val_pac & 29 & 1 & 0 & 0 & 0.018 \\
\hline Dic_fri & 26 & 2 & 0 & 0 & 0.032 \\
\hline Sar_lin & 25 & 0 & 0 & 0 & 0.047 \\
\hline Amp_anc & 1 & 56 & 0 & 0 & 0.001 \\
\hline Lau_ped & 1 & 40 & 2 & 0 & 0.016 \\
\hline Car_mai & 4 & 38 & 0 & 0 & 0.018 \\
\hline Gal_mar & 0 & 36 & 0 & 0 & 0.024 \\
\hline Hal_com & 0 & 36 & 0 & 0 & 0.019 \\
\hline Seb_fla & 0 & 36 & 0 & 0 & 0.028 \\
\hline Dic_cri & 1 & 34 & 0 & 0 & 0.037 \\
\hline Rho_sp2 & 0 & 32 & 0 & 0 & 0.030 \\
\hline Sci_tsi & 0 & 32 & 2 & 0 & 0.049 \\
\hline Sch_spe & 2 & 30 & 0 & 0 & 0.047 \\
\hline Bot_lep & 0 & 27 & 0 & 0 & 0.027 \\
\hline Hal_dup & 0 & 27 & 0 & 0 & 0.035 \\
\hline Hyp_spe & 0 & 27 & 0 & 0 & 0.032 \\
\hline Kal_spe & 0 & 27 & 0 & 0 & 0.029 \\
\hline Hal_dct & 0 & 23 & 38 & 8 & 0.045 \\
\hline Cau_lan & 0 & 1 & 70 & 0 & 0.001 \\
\hline Amp_fra & 2 & 3 & 54 & 0 & 0.002 \\
\hline Gra_deb & 0 & 0 & 51 & 0 & 0.004 \\
\hline Pad_aus & 0 & 1 & 29 & 0 & 0.048 \\
\hline Cho_sp2 & 0 & 0 & 22 & 0 & 0.040 \\
\hline Cla_lon & 0 & 0 & 22 & 0 & 0.040 \\
\hline Hlp_spe & 0 & 0 & 22 & 0 & 0.040 \\
\hline Hal_uni & 0 & 0 & 1 & 90 & 0.001 \\
\hline Hal_ova & 0 & 0 & 0 & 80 & 0.001 \\
\hline Cho_pap & 0 & 0 & 2 & 51 & 0.002 \\
\hline Gra_sal & 0 & 0 & 0 & 40 & 0.008 \\
\hline Boe_for & 0 & 2 & 0 & 33 & 0.015 \\
\hline Sar_fil & 0 & 0 & 2 & 31 & 0.030 \\
\hline
\end{tabular}

Table 4 Species with significant probabilities $(P<0.05)$ and indicator values $(\mathrm{IV}$, percentage perfect indication) for each of the biotopes (groups of DCA clusters). Biotope 1, upwelling sheltered areas (S\&M SS): MAS WC, S\&O NC; biotope 2, upwelling exposed area (S\&M US): MAS EC, S\&O SC; biotope 3 , distinct north coast entity of Socotra: SOC NC; biotope 4, seagrass beds (S\&M SG): MAS SG, SOC SG. High indicator values are marked in bold and grouped according to biotope preference. Probabilities are based on 1000 Monte Carlo permutations. The species abbreviations correspond to the species listed in Appendix 1 respective temperature regime. Values of $<2$ characterize cool temperate regions, intermediate values of 3 and 4 are indicative of warm temperate floras, and values $>5$ are found in tropical regions (Cheney, 1977; Kapraun, 1980). Bolton (1986), however, reports on inconsistently high Cheney ratios for the temperate west and south coast of South Africa. Similarly, the warm temperate Arabian Sea harbours communities with high Cheney ratios. This is especially the case for the upwelling communities MAS EC (5.2) and SOC SC (4.9). In contrast to the north Atlantic, the cooler sea temperatures apparently did not result in a proportionally higher number of brown algal species. Instead, the relative number of red algal species is higher for the upwelling communities. The Cheney ratio for the other Arabian Sea communities (S\&O NC, 2.7; MAS WC, 2.9; MAS SG, 3.1; SOC NC, 3.9) did, however, fit the general scheme, being indicative for a warm temperate flora.

The environmental parameters show two types of correlation with respect to the plant communities. The first one includes the parameters with the highest correlations for the first DCA axis. SAL_AV and SAL_NE are negatively correlated with the first axis, corresponding with the high SAL concentrations recorded for the seagrass communities (MAS SG and
SOC SG), SOC NC and S\&O NC. The absolute difference in SAL values, however, is the largest for the upwelling areas (MAS EC and S\&O SC) where the changes in SAL between both monsoons are greatest. The second type of correlation is related to the differences between the Socotra and Masirah clusters, following the resultant of both DCA axes. All CHL parameters have relatively high (positive) correlations with both axes, showing overall higher CHL concentrations for Masirah. The latter environmental variable is indicative of primary production, dependent on increased nutrient levels and thus related to the intensity of upwelling. Table 1 shows that the resultant of both axes has the highest positive correlation with CHL_SW, which corresponds to the CHL concentrations for Masirah during the SW monsoon, being the highest observed values $\left(2.20 \mu \mathrm{g} \mathrm{L}^{-1}\right)$. The CHL concentrations thus show that the effect of upwelling is more pronounced at Masirah Island. The identification of marine plant communities in the Arabian Sea opens way for integrated ecological studies and experiments to analyse the coherence in spatial variation between faunistic and floristic communities, and the abiotic and biotic effects influencing them. The indicator species should be an aid for future field studies in the area as they facilitate the identification of plant communities, 
being indicative for the corresponding environmental conditions on site.

\section{Plant communities and biotopes}

Upwelling sheltered sites (S\&M SS): S\&O NC and MAS WC

S\&O NC has the highest similarity $(0.48)$ in species composition with MAS WC. The ordination also shows an overlap between the sites of these clusters. MAS WC, on the other hand, has the highest tripartite similarity values with MAS EC (0.51), but the biogeographical affinities within the Indian Ocean are quite different between both. The biogeographical affinity of S\&O NC, on a species level, is higher for the East African coast and the Arabian Sea compared with that of MAS WC. Based on the generic records, S\&O NC and MAS WC also have similar Indian Ocean affinities, however, MAS WC again has a lower affinity for the East African coast. This shows that the Socotra community has a higher transient character from the Western Indian Ocean to the Arabian Sea, and the Masirah community comprises a higher proportion of typical Arabian Sea taxa. The biotope of upwelling sheltered sites has eighty-five species records in total. The indicator species of the plant communities, and the biotope in general, reflect the seasonally high biomass stands for this area. These communities have a macroalgal cover up to $100 \%$ and their species are indicative of seasonally high nutrient levels. Besides common Indian Ocean taxa, the endemic Nizamuddinia zanardinii grows abundantly at these partly sheltered sites.

\section{Upwelling affected sites (SたM US): S๘O SC and}

MAS EC

The ordination plot (Fig. 2) shows a gradual spread of the S\&O SC sites towards MAS EC. The tripartite similarity (Table 2) of the complete species list is high between both clusters (0.47), although both clusters have a comparably high similarity with other biotopes from their island groups, i.e. MAS EC-MAS WC (0.51) and S\&M SC-SOC NC (0.47). This is a result of the high number of species recorded for the S\&M US clusters (eighty spp. and 131 spp.) and the inclusion of transition sites between the sheltered and upwelling biotopes. In fact, a detailed analysis of vegetation quadrats of the Socotra Archipelago revealed that the south-eastern tip of Socotra is a diverse, intermediate cluster between the north and south communities (Schils \& Coppejans, 2003). This low-scale resolution has not been detected in the analyses of the species inventories, which is reflected in the high number of species recorded for S\&M US: 158 species. The indicator species of this biotope are largely Rhodophyta. These red algae are common elements of species rich communities, often associated with a well-developed understory flora.

\section{Distinct entity of Socotra's north coast (SOC NC)}

This cluster was retained from grouping, it is characterized by a high species richness (seventy-six spp.) and its affinities with other clusters differ between the analyses. In the DCA, the sites of SOC NC are plotted in between those of S\&M SG and S\&O SC. Its tripartite similarity is highest with S\&O SC (0.47), the cluster with the highest species richness. As discussed under S\&M US, S\&O SC comprises transition zones between Socotra's north and south coast, increasing the affinity between SOC NC and S\&O SC. The biogeographical analyses of SOC NC, however, shows a similar trend as the communities of S\&M SS, most pronounced in the generic analysis. The indicator species analysis provides an insight into the characteristic species of this cluster: these species are common Indian Ocean algae growing in sheltered environments, often associated with fine sediment (sandy patches or hard substratum covered by a fine sand layer). Although typified by different habitat specific species, this biotope is regarded as a subentity of the upwelling sheltered shores (S\&M SS). The macroalgal stands of the SOC NC sites are governed by high physical stress (bioerosion due to sand scouring) and, hence, characterized by a much lower biomass and substratum cover in comparison to S\&M SS sites.

Seagrass communities (S\&M SG): MAS SG and SOC SG In the DCA plot, the sites of both islands cluster together. SOC SG has the greatest similarity with MAS SG, the tripartite similarity between the seagrass communities of both islands being low, however. This results from the speciespoor (five spp.) seagrass beds at Qalansiyah lagoon (Socotra), predominantly comprised of the seagrasses Halodule uninervis, Halophila ovalis and Thalassia hemprichii. The indicator species of this biotope as a whole are well known to occur in seagrass beds, which in turn are linked to areas of heavy sedimentation. Analogous to the discussion of SOC NC, this entity can be regarded as a subentity of S\&M SS, constituting a specific biotope within the sheltered coasts of both islands. This is reflected in the rather high similarity values of the species rich seagrass communities of MAS SG with SOC NC, S\&O NC and MAS WC.

\section{Biogeography of the Arabian Sea}

Sheppard et al. (1992) suspect that most of the biotic distributions in the Arabian Seas (comprising the Red Sea, Gulf of Aden, Arabian Sea, Gulf of Oman and Persian Gulf) are no more than chance distributions and that the area as a whole constitutes a single biogeographical subregion. Besides the odd exception (e.g. high local endemism of butterflyfish), Sheppard et al. (1992) believe that biogeographical patterns result from insufficient time for complete dispersal after the start of the Holocene and inadequate 'mixing' of fauna throughout the various suitable habitats in the Indian Ocean. These authors remark that a designation on a smaller biogeographical scale might be possible for some fish, yet for other groups, notably the plants, there is no justification for any subprovincial division. Similarly, van den Hoek (1984) and Adey \& Steneck (2001) identify one tropical Indo-West Pacific Region, incorporating all the Arabian Seas. The analyses of macroalgal assemblages in the Arabian Sea s.s. (present paper; Schils \& Coppejans, 2003), 
however, detect distinct subtidal plant communities and biotopes according to differences in the governing environmental parameters. Of these, the upwelling affected plant communities typify a peculiar Arabian Sea flora. Certain species of these communities show disjunct distribution patterns throughout the Indo-Pacific and are also suspected to be of biogeographical importance within the larger Arabian region. Combined with the discovery of an increasing number of endemic algae, this leaves us to conclude that the Arabian Sea constitutes a phytogeographical subprovince within the Indo-Pacific and the larger Arabian region. Prospective fieldwork at the transition area from the Arabian Sea to the Gulf of Oman would extend the investigated area considerably, being excellent to test biogeographical (dis)continuities towards the border of the Arabian Sea and the Gulf of Oman. Questions of interest include: (1) the degree of divergence from the East African flora, (2) the impact of upwelling on these communities, (3) the use of this location in a geographical gradient, from the Arabian Sea over the Gulf of Oman towards the Arabian Gulf, in order to test the macroalgal turnover according to the decrease in substratum availability (sedimentary coasts as a biogeographical barrier). Recently, the first temperature loggers have been installed at Masirah Island (Wilson, 1999) in an attempt to achieve accurate coastal data on a detailed temporal and spatial scale. These precise coastal data are needed for understanding the relationship between the environmental conditions and the biotic interactions (e.g. competition between algae and corals).

\section{CONCLUSIONS}

The analysis of two upwelling areas within the Arabian Sea presented here shows (1) the identification of similar plant communities (upwelling affected areas, upwelling sheltered areas, seagrass communities) at both islands, based on their taxon (species and genera) composition, and (2) an increased divergence of the East African flora from Socotra towards Masirah. In this respect the Socotra Archipelago is a stepping stone between marine plant communities of the East African coast and the Arabian Sea. The plant communities of the upwelling sheltered sites can be grouped in three distinct biotopes depending on the degree of exposure (reflected in the degree of sedimentation): (1) the seagrass beds in the protected embayments (MAS SG and SOC SG), (2) a floristic entity related to a sand covered substratum (SOC NC, including a few seagrass communities of protected sites on Socotra's south coast), and (3) the macroalgal communities of more exposed sites (often associated with well-developed coral communities; S\&O NC and MAS WC). The peculiar marine floristics that characterize the uniqueness of the Arabian Sea predominantly occur at the upwelling affected shores. The plant communities of these areas show a marked biogeographical affinity with distant areas (South Africa and Western Australia; Fig. 4a,b) because of the disjunct distribution pattern of certain taxa (Wynne, 2000; Schils \& Coppejans, 2002; Schils et al., 2003a). The species richness of the upwelling affected communities is the highest, with a large proportion of red algae (comprising most of the indicator species of this biotope) in the total species composition (Fig. 3a,b). This biotope also includes speciesrich overlap communities towards the upwelling sheltered sites being, however, clearly characterized as upwelling communities.

In comparison with faunistic studies of the area (Apel, 2000), it is important to note that the characteristic plant communities of the Arabian Sea are situated at opposing biotopes where faunistic (e.g. corals, decapods, etc.) diversity, species richness and endemism thrive. The evolution towards distinct biogeographical entities (e.g. centre of endemism along the southern Arabian Peninsula) at these favourable biotopes within the Indian Ocean is most likely the result of vicariation events. The environmental barriers (warmer and less nutrient-enriched waters) isolating the macroalgal communities are the favourable biotopes of the faunistic communities, and vice versa. The occurrence of these opposing biotopes in a restricted geographical area, make both islands a haven for both the characteristic floristic and faunistic communities of the Arabian Sea. Consequently, these islands can be reasonably well managed from a logistical and financial point of view, serving as ideal subjects of intended conservation efforts (e.g. Socotra Biodiversity Project, GEF/Ned/UNDP) to preserve the unique biotic communities of the Arabian Sea.

\section{ACKNOWLEDGMENTS}

Thanks are expressed to the Senckenberg Research Institute (Michael Apel and Fareed Krupp; Germany) and the Ardoukoba Organization (France) for the excellent field trip preparations to the Socotra Archipelago and Masirah Island, respectively. We are grateful to Frederik Leliaert and Olivier De Clerck for their help in identifying Cladophorales and Dictyota specimens. Tom Schils is indebted to the Fund for Scientific Research Flanders (FWO, Belgium) for his research assistant grant.

\section{REFERENCES}

Adey, W.H. \& Steneck, R.S. (2001) Thermography over time creates biogeographic regions: a temperature/space/timeintegrated model and an abundance-weighted test for benthic marine algae. Journal of Phycology, 37, 677-698.

Apel, M. (2000) Survey of the decapod Crustacea of Socotra. Conservation and sustainable use of biodiversity of Socotra Archipelago. Marine habitat, biodiversity and fisheries surveys and management. Progress report of phase III (ed. by M. Apel and K.I. Hariri), pp. 107-126. Senckenberg Research Institute, Frankfurt a.M.

Bolton, J.J. (1986) Marine phytogeography of the Benguela upwelling region on the west coast of southern Africa: a temperature dependent approach. Botanica Marina, 29, 251256.

ter Braak, C.J.F. (1988) CANOCO - a FORTRAN program for canonical community ordination by (partial) (detrended) (canonical) correspondence analysis, principal component 
analysis and redundancy analysis (version 2.1), p. 95. Manual, TNO, Wageningen.

ter Braak, C.J.F. \& Šmilauer, P. (1998) CANOCO reference manual and user's guide to Canoco for Windows: software for canonical community ordination (version 4), p. 352. Microcomputer Power, Ithaca, New York.

Børgesen, F. (1934) Some marine algae from the northern part of the Arabian Sea with remarks on their geographical distribution. Kongelige Danske Videnskabernes Selskab, Biologiske Meddelelser, 11, 1-72.

Cheney, D.F. (1977) R \& C/P, a new and improved ratio for comparing seaweed floras. Journal of Phycology, 13 (Suppl.), 12.

Coppejans, E., Leliaert, F. \& De Clerck, O. (2000) Annotated list of new records of marine macroalgae for Kenya and Tanzania since Isaac's and Jaasund's publications. Biologisch Jaarboek Dodonaea, 67, 31-93.

Critchley, A.T., Aken, M.E., Bandeira, S. \& Kalk, M. (1997) A revised list of seaweeds from Inhaca Island, Mozambique. South African Journal of Botany, 63, 426-435.

De Clerck, O. (2003) The genus Dictyota (Dictyotales, Phaeophyta) in the Indian Ocean. Opera Botanica Belgica, 13, 204.

De Clerck, O. \& Coppejans, E. (1996) Marine algae of the Jubail Marine Wildlife Sanctuary, Saudi Arabia. A marine wildlife sanctuary for the Arabian Gulf. Environmental research and conservation following the 1991 Gulf War oil spill (ed. by F. Krupp, A.H. Abuzinada and I.A. Nader), pp. 199-289. NCWCD, Riyadh and Senckenberg Research Institute, Frankfurt a.M.

De Clerck, O. \& Coppejans, E. (1999) Two new species of Dictyota (Dictyotales, Phaeophyta) from the Indo-Malayan region. Phycologia, 38, 184-194.

De Clerck, O., Engledow, H.R., Bolton, J.J., Anderson, R.J. \& Coppejans, E. (2002) Twenty marine benthic algae new to South Africa, with emphasis on the flora of Kwazulu-Natal. Botanica Marina, 45, 413-431.

Dickie, G. (1888) Algae. Botany of Socotra (ed. by I.B. Balfour). Transactions of the Royal Society of Edinburgh, 31, 394401.

van den Hoek, C. (1984) World-wide latitudinal and longitudinal seaweed distribution patterns and their possible causes, as illustrated by the distribution of Rhodophytan genera. Helgoländer Meeresuntersuchungen, 38, 227-257.

Holmes, E.M. (1903) Seaweeds of Abd-El-Kuri. The natural history of Socotra and Abd-El-Kuri (ed. by H.O. Forbes), pp. 567-568. Young \& Sons, Liverpool.

Huisman, J.M. (2000) Marine plants of Australia, p. 300. University of Western Australia Press, Nedlands, Western Australia.

Kapraun, D.F. (1980) Floristic affinities of North Carolina inshore benthic marine algae. Phycologia, 19, 245-252.

Kemp, J.M. (1998a) The occurrence of Nizamuddinia zanardinii (Schiffner) P.C. Silva (Phaeophyta: Fucales) at the Socotra Archipelago. Botanica Marina, 41, 345-348.

Kemp, J.M. (1998b) Zoogeography of the coral reef fishes of the Socotra Archipelago. Journal of Biogeography, 25, 919933.

Leliaert, F. (2000) Marine benthic macroalgae and seagrasses of the Socotra Archipelago. Conservation and sustainable use of biodiversity of Socotra Archipelago. Marine habitat, biodiversity and fisheries surveys and management. Progress report of phase III (ed. by M. Apel and K.I. Hariri), pp. 13-48. Senckenberg Research Institute, Frankfurt a.M.

McCune, B. \& Mefford, M.J. (1999) PC-ORD. Multivariate analysis of ecological data, Version 4.17. MjM Software, Gleneden Beach, Oregon.

Nizamuddin, M. \& Campbell, A.C. (1995) Glossophorella, a new genus of the family Dictyotaceae (Dictyotales - Phaeophyceae) and its ecology from the coast of the Sultanate of Oman. Pakistan Journal of Botany, 27, 257-262.

Ormond, R.F.G. \& Banaimoon, S.A. (1994) Ecology of intertidal macroalgal assemblages on the Hadramout coast of southern Yemen, an area of seasonal upwelling. Marine Ecology Progress Series, 105, 105-120.

Randall, J.E. \& Hoover, J.P. (1995) Scarus zhufar, a new species of parrotfish from southern Oman, with comments on endemism of the area. Copeia, 683-688.

Schaffelke, B. \& Klumpp, D.W. (1998) Short-term nutrient pulses enhance growth and photosynthesis of the coral reef macroalga Sargassum baccularia. Marine Ecology Progress Series, 170, 95-105.

Schils, T. (1999) Macroalgae. Preliminary Report Scientific Mission Oman 99, Sultanate of Oman, November-December 1999 (ed. by S. Planes and R. Galzin), pp. 22-23, 64-69. Ardoukoba, Paris.

Schils, T. (2002) Macroalgal assemblages of the Socotra Archipelago. Conservation and sustainable use of biodiversity of Socotra Archipelago. Marine habitat, biodiversity and fisheries surveys and management. Final report of phase III (ed. by M. Apel, K.I. Hariri and F. Krupp), pp. 383-389. Senckenberg Research Institute, Frankfurt a.M.

Schils, T. \& Coppejans, E. (2002) Gelatinous red algae of the Arabian Sea, including Platoma heteromorphum sp. nov. (Gigartinales, Rhodophyta). Phycologia, 41, 254-267.

Schils, T. \& Coppejans, E. (2003). Spatial variation in subtidal plant communities around the Socotra Archipelago and their biogeographic affinities within the Indian Ocean. Marine Ecology Progress Series, 251, 103-114.

Schils, T., De Clerck, O. \& Coppejans, E. (2003a) The red-algal genus Reticulocaulis from the Arabian Sea, including $R$. obpyriformis Schils, sp. nov., with comments on the family Naccariaceae. Phycologia, 42, 44-55.

Schils, T., Huisman, J.M. \& Coppejans, E. (2003b) Chamaebotrys erectus sp. nov. (Rhodymeniales, Rhodophyta) from the Socotra Archipelago, Yemen. Botanica Marina, 46, 2-8.

Sheppard, C.R.C. \& Salm, R.V. (1988) Reef and coral communities of Oman, with the description of a new coral species (Order Scleractinia, genus Acanthastrea). Journal of Natural History, 22, 263-279.

Sheppard, C.R.C., Price, A.R.G. \& Roberts, C.A. (1992) Marine ecology of the Arabian region, p. 359. Academic Press Ltd, London.

Silva, P.C., Basson, P.W. \& Moe, R.L. (1996) Catalogue of the benthic marine algae of the Indian Ocean. University of California Publications in Botany, 79, 1-1259.

Tulloss, R.E. (1997) Assessment of similarity indices for undesirable properties and a new tripartite similarity index based on cost functions. Mycology in sustainable development: expanding concepts, vanishing borders (ed. by M.E. 
Palm and I.H. Chapela), pp. 122-143. Parkway Publishers, Boone, North Carolina.

de Vaugelas, J. (2001) Echiurans. 'Oman 99' final scientific report, pp. 37-40. Ardoukoba, Paris.

Wilson S.C. 1999. Corals. Preliminary Report Scientific Mission Oman 99, Sultanate of Oman, November-December 1999 (ed. by S. Planes and R. Galzin), pp. 28-29, 76-77. Ardoukoba, Paris.

Wilson, S.C. (2000) Northwest Arabian Sea and Gulf of Oman. Seas at the millennium: an environmental evaluation, Vol. II (ed. by C. Sheppard), pp. 17-33. Elsevier Science, Amsterdam.

Wilson, S.C. \& Klaus, R. (2000) The Gulf of Aden. Seas at the Millennium: an environmental evaluation, Vol. II (ed. by C. Sheppard), pp. 47-61. Elsevier Science, Amsterdam.

Wynne, M.J. (1999a) Pseudogrinnellia barratiae gen. et sp. nov., a new member of the red algal family Delesseriaceae from the Sultanate of Oman. Botanica Marina, 42, 37-42.

Wynne, M.J. (1999b) New records of benthic marine algae from the Sultanate of Oman. Contributions of the University of Michigan Herbarium, 22, 189-208.

Wynne, M.J. (2000) Further connections between the benthic marine algal floras of the northern Arabian Sea and Japan. Phycological Research, 48, 211-220.

Wynne, M.J. (2001) Stirnia prolifera gen. et sp. nov. (Rhodymeniales, Rhodophyta) from the Sultanate of Oman. Botanica Marina, 44, 163-169.

Wynne, M.J. \& Banaimoon, S.A. 1990. The occurrence of Jolyna laminarioides (Phaeophyta) in the Arabian Sea and the
Indian Ocean and a new report of Melanothamnus somalensis (Rhodophyta). Botanica Marina, 33, 213-218.

Wynne, M.J. \& Jupp, B.P. (1998) The benthic marine algal flora of the Sultanate of Oman: new records. Botanica Marina, 41, 7-14.

Wynne, M.J. \& Leliaert, F. (2001) Pedobesia simplex (Kützing) comb. nov. (Chlorophyta), a new name for P. lamourouxii and its first report from the Indian Ocean. Cryptogamie Algologie, 22, 3-14.

\section{BIOSKETCHES}

Tom Schils is a researcher of the Fund for Scientific Research at Ghent University, Belgium. His research interests include the ecology, biogeography and taxonomy of macroalgae, currently focusing on the flora of the Arabian Seas.

Eric Coppejans is a Professor of Botany at Ghent University and has carried out phycological research in the Indo-Pacific, the Mediterranean Sea and the Atlantic for more than three decades. 
Appendix I Species recorded for Masirah Island and the Socotra Archipelago, including the abbreviations used in the analyses and the cluster occurrences of each species. Cluster abbreviations as in Fig. 1

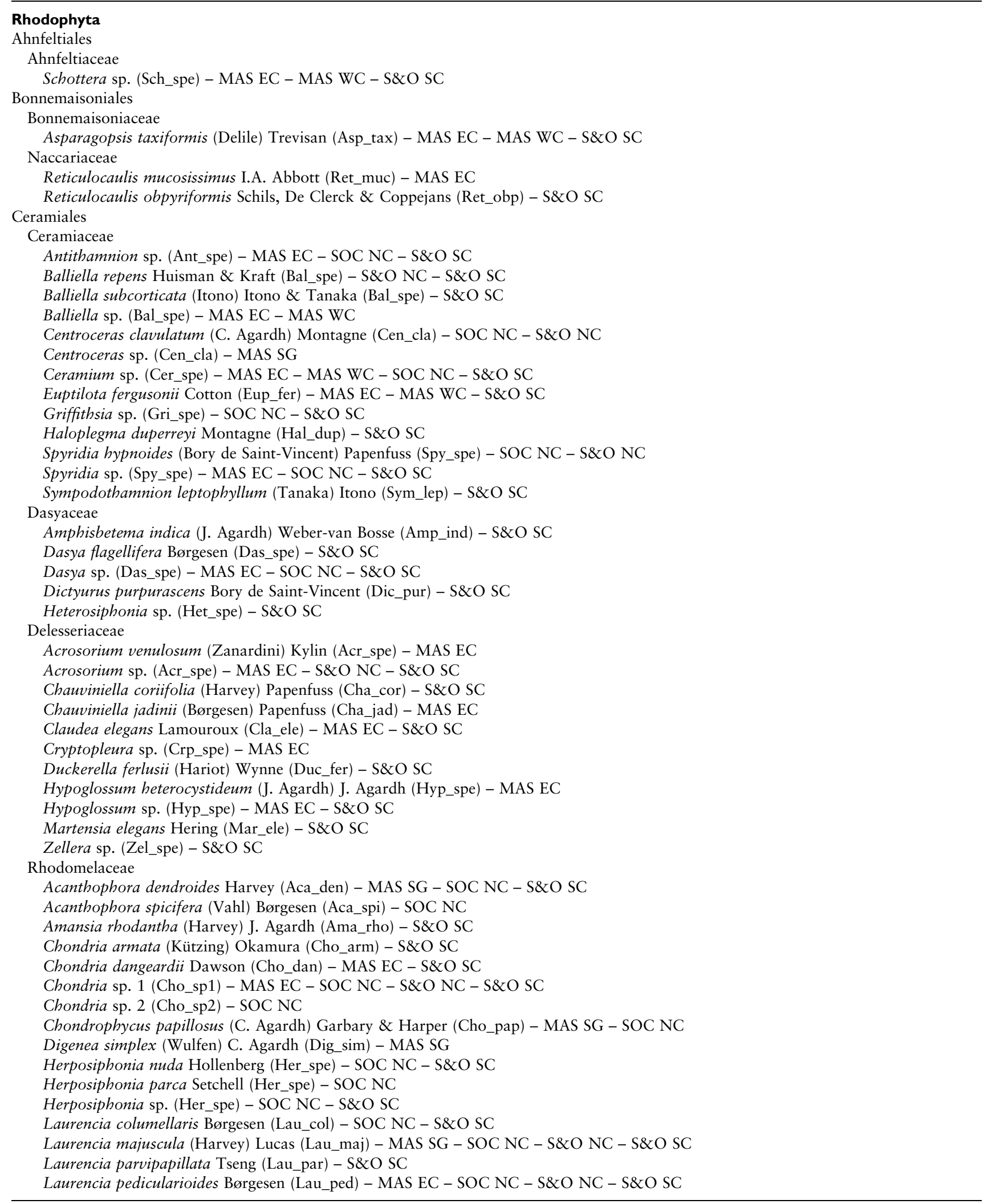


Appendix I continued

Laurencia perforata (Bory de Saint-Vincent) Montagne (Lau_per) - MAS WC - S\&O SC - SOC SG

Leveillea jungermannioides (Hering \& G. Martens) Harvey (Lev_jun) - MAS WC - MAS SG - S\&O NC

Lophocladia sp. (Lop_spe) - S\&O SC

Melanamansia sp. (Mel_spe) - MAS EC - SOC NC

Melanothamnus somalensis Bornet \& Falkenberg (Mel_som) - MAS WC

Osmundaria melvillii (J. Agardh) R. Norris (Osm_mel) - SOC NC - S\&O SC

Polysiphonia sp. (Pol_spe) - MAS WC - S\&O SC

Tolypiocladia glomerulata (C. Agardh) Schmitz (Tol_glo) - MAS WC

Corallinales

Corallinaceae

Amphiroa anceps (Lamarck) Decaisne (Amp_anc) - MAS EC - MAS WC - S\&O SC

Amphiroa beauvoisii Lamouroux (Amp_bea) - MAS EC - MAS WC - S\&O NC - S\&O SC

Amphiroa fragilissima (Linnaeus) Lamouroux (Amp_fra) - SOC NC - S\&O NC - S\&O SC

Amphiroa misakiensis Yendo (Amp_bea) - MAS EC - S\&O NC

Amphiroa rigida Lamouroux (Amp_fra) - SOC NC - S\&O NC - S\&O SC

Amphiroa sp. (Amp_bea) - MAS SG

Haliptilon sp. (Hlp_spe) - SOC NC

Jania sp. (Jan_spe) - MAS WC - MAS SG - SOC NC - S\&O NC - S\&O SC

Sporolithaceae

Sporolithon sp. (Spo_spe) - MAS SG - S\&O NC

Gelidiales

Gelidiaceae

Pterocladia cf. caloglossoides (Howe) Dawson (Pte_cfe) - MAS EC - MAS WC - S\&O NC - S\&O SC

Pterocladiella caerulescens (Kützing) Santelices \& Hommersand (Pte_cae) - MAS EC - MAS WC - MAS SG - SOC NC -

S\&ONC - S\&O SC

Gelidiellaceae

Gelidiella acerosa (Forsskål) J. Feldmann \& G. Hamel (Gel_ace) - MAS WC - MAS SG - S\&O NC

Gelidiella pannosa (Feldmann) Feldmann \& Hamel (Gel_pan) - S\&O NC

Gigartinales

Cystocloniaceae

Calliblepharis fimbriata (Greville) Kützing (Cal_fim) - MAS EC

Dumontiaceae

Dudresnaya capricornica Robins \& Kraft (Dud_cap) - S\&O SC

Gibsmithia larkumii Kraft (Gib_lar) - S\&O SC

Hypneaceae

Hypnea charoides Lamouroux/valentiae (Turner) Montagne complex (Hyp_cha) - MAS SG - SOC NC - S\&O NC - S\&O SC - SOC SG Hypnea musciformis (Wulfen) Lamouroux (Hyp_mus) - MAS EC - S\&O NC - S\&O SC

Hypnea pannosa J. Agardh (Hyp_pan) - MAS WC - S\&O NC - S\&O SC

Hypnea spinella (C. Agardh) Kützing (Hyp_cha) - MAS EC - MAS SG - SOC NC - S\&O NC - S\&O SC - SOC SG

Kallymeniaceae

Kallymenia crassiuscula Okamura 1934 (Kal_spe) - MAS EC

Kallymenia sp. (Kal_spe) - MAS EC - S\&O SC

Rhizophyllidaceae

Portieria hornemannii (Lyngbye) P. Silva (Por_hor) - MAS EC - MAS WC - SOC NC - S\&O NC - S\&O SC

Sarcodiaceae

Sarcodia montagneana (J. Hooker \& Harvey) J. Agardh (Sar_mon) - MAS EC - MAS WC - S\&O SC

Solieriaceae

Callophycus serratus (Harvey ex Kützing) P.C. Silva (Cal_ser) - S\&O SC

Sarconema filiforme (Sonder) Kylin (Sar_fil) - MAS SG - SOC NC

Sarconema sp. (Sar_fil) - SOC NC

Solieria robusta (Greville) Kylin (Sol_rob) - MAS EC - S\&O SC

Gracilariales

Gracilariaceae

Gracilaria corticata (J. Agardh) J. Agardh (Gra_mil) - MAS WC - MAS SG - SOC NC - S\&O SC

Gracilaria debilis (Forsskål) Børgesen (Gra_deb) - MAS EC - SOC NC

Gracilaria millardetii (Montagne) J. Agardh (Gra_mil) - MAS EC - SOC NC - S\&O NC - S\&O SC

Gracilaria salicornia (C. Agardh) Dawson (Gra_sal) - MAS SG

Gracilaria textorii (Suringar) De Toni (Gra_tex) - MAS EC - S\&O SC

Halymeniales

Halymeniaceae

Carpopeltis maillardii (Montagne \& Millardet) Chiang (Car_mai) - MAS EC - MAS WC - S\&O NC - S\&O SC 
Appendix I continued

Carpopeltis sp. (Car_mai) - MAS EC

Cryptonemia sp. (Cry_spe) - SOC NC - S\&O SC

Halymenia durvillei Bory de Saint-Vincent (Hal_por) - SOC NC - S\&O SC

Halymenia porphyraeformis Parkinson (Hal_por) - MAS EC - MAS WC

Peyssonneliaceae

Peyssonnelia sp. (Pey_spe) - MAS EC - MAS WC - SOC NC - S\&O NC - S\&O SC

Sebdeniaceae

Sebdenia flabellata (J. Agardh) Parkinson (Seb_fla) - MAS EC - S\&O SC

Nemaliales

Galaxauraceae

Galaxaura marginata (Ellis \& Solander) Lamouroux (Gal_mar) - MAS EC - S\&O SC

Galaxaura obtusata (Ellis \& Solander) Lamouroux (Gal_obt) - MAS EC - S\&O SC

Galaxaura rugosa (Ellis \& Solander) Lamouroux (Gal_rug) - S\&O SC

Scinaia complanata (Collins) Cotton (Sci_com) - MAS EC

Scinaia hormoides Setchell (Sci_mon) - MAS EC

Scinaia moniliformis J. Agardh (Sci_mon) - S\&O SC

Scinaia tsinglanensis Tseng (Sci_tsi) - MAS EC - SOC NC - S\&O SC

Tricleocarpa cylindrica (Ellis \& Solander) Huisman \& Borowitzka (Tri_cyl) - SOC NC - S\&O SC

Tricleocarpa fragilis (Linnaeus) Huisman \& Townsend (Tri_fra) - S\&O SC

Liagoraceae

Liagora ceranoides Lamouroux (Lia_spe) - SOC NC

Liagora sp. (Lia_spe) - MAS WC - SOC NC

Nemastomatales

Nemastomataceae

Predaea laciniosa Kraft (Pre_lac) - MAS EC - S\&O SC

Predaea weldii Kraft \& I.A. Abbott (Pre_wel) - MAS EC - MAS WC

Schizymeniaceae

Platoma heteromorphum Schils (Pla_het) - MAS EC

Titanophora pikeana (Dickie) J. Feldmann (Tit_pik) - S\&O SC

Plocamiales

Plocamiaceae

Plocamium fimbriatum Wynne (Plo_fim) - MAS EC - MAS WC

Plocamium microcladioides South \& N.M. Adams (Plo_mic) - MAS EC - MAS WC

Plocamium telfairiae (J. D. Hooker \& Harvey) Harvey ex Kützing (Plo_tel) - MAS EC - MAS WC

Plocamium telfairiae (J. D. Hooker \& Harvey) Harvey ex Kützing var. uncinatum (Plo_tel) - MAS EC - MAS WC

Rhodymeniales

Champiaceae

Champia compressa Harvey (Cha_com) - MAS EC - MAS WC - SOC NC - S\&O SC

Champia indica Børgesen (Cha_ind) - S\&O SC

Champia parvula (C. Agardh) Harvey (Cha_com) - MAS SG - SOC NC - S\&O NC - S\&O SC

Faucheaceae

Fauchea sp. (Fau_spe) - MAS EC

Gloiocladia sp. (Glo_spe) - S\&O SC

Lomentariaceae

Gelidiopsis sp. (Gel_var) - MAS EC - SOC NC - S\&O NC - S\&O SC

Gelidiopsis variabilis J. Agardh (Schmitz) (Gel_var) - MAS EC - SOC NC - S\&O SC

Lomentaria strumosa Wynne (Lom_stru) - MAS WC

Rhodymeniaceae

Asteromenia peltata (W.R. Taylor) Huisman \& Millar (Ast_pel) - S\&O NC - S\&O SC

Botryocladia leptopoda (J. Agardh) Kylin (Bot_lep) - S\&O SC

Botryocladia skottsbergii (Børgesen) Levring (Bot_sko) - S\&O SC

Chamaebotrys sp. (Chm_spe) - S\&O SC

Chrysymenia grandis Okamura (Chr_gra) - MAS EC - S\&O SC

Chrysymenia sp. (Chr_spe) - MAS EC - S\&O SC

Coelarthrum opuntia (Endlicher) Børgesen (Coe_opu) - SOC NC - S\&O SC

Erythrocolon podagricum J. Agardh (Ery_pod) - S\&O SC

Rhodymenia sp. 1 (Rho_sp1) - MAS EC - MAS WC

Rhodymenia sp. 2 (Rho_sp2) - MAS EC 
Appendix I continued

\section{Phaeophyta}

Dictyotales

Dictyotaceae

Dictyopteris delicatula Lamouroux (Dic_del) - S\&O SC

Dictyopteris macrocarpa (Areschoug) O. Schmidt (Dic_mac) - MAS EC - S\&O SC

Dictyopteris membranacea (Stackhouse) Batters (Dic_pol) - SOC NC

Dictyopteris polypodioides (De Candolle) Lamouroux (Dic_pol) - SOC NC - S\&O NC - S\&O SC

Dictyota bartayresiana Lamouroux (Dic_bar) - MAS EC - MAS WC - SOC NC

Dictyota cervicornis Kützing (Dic_cer) - MAS SG - SOC NC - S\&O NC - S\&O SC

Dictyota ceylanica Kützing (Dic_cey) - MAS EC - MAS WC - SOC NC - S\&O NC - S\&O SC

Dictyota ciliolata Kützing (Dic_cil) - MAS EC - MAS WC

Dictyota crispata Lamouroux (Dic_cri) - MAS EC - MAS WC - S\&O SC

Dictyota dichotoma (Hudson) Lamouroux var. intricata (C. Agardh) Greville (Dic_cer) - S\&O SC

Dictyota friabilis Setchell (Dic_fri) - MAS EC - S\&O NC - S\&O SC

Dictyota grossedentata De Clerck \& Coppejans (Dic_gro) - S\&O SC

Dictyota stolonifera Dawson (Dic_sto) - S\&O SC

Lobophora variegata (Lamouroux) Womersley ex Oliveira (Lob_var) - MAS EC - MAS WC - MAS SG - S\&O NC - S\&O SC

Padina antillarum (Kützing) Piccone (Pad_ant) - MAS EC

Padina australis Hauck (Pad_aus) - SOC NC - S\&O SC

Padina boergesenii Allender \& Kraft (Pad_boe) - MAS SG - SOC NC - S\&O NC - S\&O SC

Padina dubia Hauck (Pad_gym) - MAS EC - MAS WC

Padina elegans Koh ex Womersley (Pad_ele) - MAS EC - S\&O SC

Padina glabra Gaillard (Pad_gym) - MAS EC - MAS WC

Padina gymnospora (Kützing) Sonder (Pad_gym) - SOC NC - S\&O NC

Padina minor Yamada (Pad_min) - MAS SG

Spatoglossum asperum J. Agardh (Spa_asp) - MAS EC - MAS WC - SOC NC - S\&O NC - S\&O SC

Stoechospermum polypodioides (Lamouroux) J. Agardh (Sto_pol) - MAS EC - MAS WC - MAS SG - SOC NC - S\&O NC

Stypopodium sp. (Sty_spe) - SOC NC - S\&O SC

Ectocarpales

Ectocarpaceae

Ectocarpus sp. (Ect_spe) - SOC NC - S\&O SC

Fucales

Cystoseiraceae

Cystoseira indica (Thivy \& Doshi) Mairh (Cys_ind) - MAS SG

Cystoseira myrica (S. Gmelin) C. Agardh (Cys_myr) - MAS SG

Hormophysa cuneiformis (J. Gmelin) P. Silva (Hor_cun) - SOC NC

Sargassaceae

Nizamuddinia zanardinii (Schiffner) P. Silva (Niz_zan) - MAS WC - S\&O NC

Sargassum angustifolium C. Agardh (Sar_ang) - SOC NC - S\&O SC

Sargassum decurrens (R. Brown ex Turner) C. Agardh (Sar_dec) - MAS WC - S\&O SC

Sargassum latifolium (Turner) C. Agardh (Sar_lat) - MAS EC - MAS WC - S\&O SC

Sargassum linearifolium (Turner) C. Agardh (Sar_lin) - S\&O NC

Sargassum oligocystum Montagne (Sar_oli) - MAS WC - MAS SG

Sargassum piluliferum (Turner) C. Agardh (Sar_pil) - MAS WC - MAS SG

Sargassum sp. (Sar_sp1) - MAS WC - MAS SG

Turbinaria ornata (Turner) J. Agardh (Tur_orn) - MAS WC - S\&O NC - S\&O SC

Scytosiphonales

Chnoosporaceae

Chnoospora implexa J. Agardh (Chn_imp) - S\&O NC

Scytosiphonaceae

Colpomenia sinuosa (Mertens ex Roth) Derbès \& Solier (Col_sin) - SOC NC - S\&O SC

Hydroclathrus clathratus (C. Agardh) Howe (Hyd_cla) - SOC NC

Rosenvingea intricata (J. Agardh) Børgesen (Ros_int) - S\&O NC - S\&O SC

Chlorophyta

Bryopsidales

Bryopsidaceae

Bryopsis hypnoides Lamouroux (Bry_spe) - S\&O SC

Bryopsis indica A. Gepp \& E. Gepp (Bry_spe) - MAS EC - MAS WC - S\&O SC

Bryopsis pennata Lamouroux (Bry_spe) - MAS WC

Bryopsis sp. (Bry_spe) - S\&O NC 
Appendix I continued

Pseudobryopsis hainanensis Tseng (Pse_spe) - MAS EC - MAS SG

Caulerpaceae

Caulerpa brachypus Harvey (Cau_bra) - S\&O SC

Caulerpa cupressoides (Vahl) C. Agardh (Cau_cup) - SOC NC

Caulerpa lanuginosa J. Agardh (Cau_lan) - SOC NC - S\&O SC

Caulerpa lentillifera J. Agardh (Cau_len) - MAS SG - SOC NC - S\&O SC

Caulerpa mexicana Sonder ex Kützing (Cau_mex) - MAS EC - MAS SG - SOC NC - S\&O SC

Caulerpa peltata Lamouroux (Cau_pel) - MAS EC - MAS WC - S\&O NC - S\&O SC

Caulerpa racemosa (Forsskål) J. Agardh (Cau_rac) - MAS EC - MAS WC - MAS SG - S\&O SC

Caulerpa scalpelliformis (R. Brown ex Turner) C. Agardh (Cau_sca) - MAS SG - SOC NC - S\&O SC

Caulerpa serrulata (Forsskål) J. Agardh (Cau_ser) - MAS WC - MAS SG

Caulerpa sertularioides (S. Gmelin) Howe (Cau_set) - MAS SG - SOC NC - S\&O SC

Codiaceae

Codium arabicum Kützing (Cod_ara) - MAS WC - MAS SG - SOC NC

Codium dwarkense Børgesen (Cod_dwa) - MAS EC - MAS WC - SOC NC - S\&O NC - S\&O SC

Codium ovale Zanardini (Cod_ova) - MAS EC

Codium tenue (Kützing) Kützing (Cod_ten) - MAS EC

Derbesiaceae

Pedobesia simplex (Kützing) M.J. Wynne \& Leliaert (Ped_sim) - S\&O SC

Udoteaceae

Avrainvillea lacerata Harvey ex J. Agardh (Avr_lac) - SOC NC - S\&O SC

Chlorodesmis fastigiata (C. Agardh) Ducker (Chl_fas) - S\&O NC

Chlorodesmis sp. (Chl_fas) - MAS EC - MAS SG

Halimeda copiosa Goreau \& Graham/minima (W.R. Taylor) Colinvaux (Hal_com) - S\&O SC

Halimeda cuneata Hering (Hal_dct) - SOC NC - S\&O SC

Halimeda discoidea Decaisne (Hal_dct) - MAS SG - SOC NC - S\&O SC

Halimeda stuposa W.R. Taylor (Hal_stu) - SOC NC - S\&O SC

Halimeda tuna (Ellis \& Solander) Lamouroux (Hal_dct) - MAS EC - MAS WC - MAS SG - SOC NC - S\&O SC

Udotea indica A. Gepp \& E. Gepp (Udo_ind) - MAS SG - SOC NC - S\&O SC

Cladophorales

Anadyomenaceae

Microdictyon sp. (Mic_spe) - S\&O SC

Cladophoraceae

Chaetomorpha sp. (Cht_spe) - MAS SG - SOC NC - S\&O SC

Cladophora catenata (Linnaeus) Kützing (Cla_cat) - MAS EC

Cladophora coelothrix Kützing (Cla_coe) - MAS SG - SOC NC - S\&O SC

Cladophora prolifera (Roth) Kützing (Cla_pro) - SOC NC

Cladophora sericea (Hudson) Kützing (Cla_ser) - MAS WC

Cladophora vagabunda (Linnaeus) van den Hoek (Cla_vag) - MAS EC - MAS WC - SOC NC - S\&O NC - S\&O SC

Cladophora sp., section Longi-articulatae (Cla_lon) - SOC NC

Siphonocladaceae

Boergesenia forbesii (Harvey) J. Feldmann (Boe_for) - MAS SG - S\&O SC

Boodlea composita (Harvey) Brand (Boo_com) - SOC NC

Chamaedoris auriculata Børgesen (Cha_aur) - SOC NC - S\&O SC

Chamaedoris delphinii (Hariot) J. Feldmann \& Børgesen (Cha_del) - S\&O NC

Cladophoropsis herpestica (Montagne) Howe (Cla_her) - MAS WC - MAS SG

Cladophoropsis sundanensis Reinbold (Cla_sun) - MAS SG

Dictyosphaeria cavernosa (Forsskål) Børgesen (Dic_cav) - S\&O NC

Phyllodictyon anastomosans (Harvey) Kraft \& M.J. Wynne (Phy_spe) - S\&O NC - S\&O SC

Siphonocladus tropicus (P. Crouan \& H. Crouan) J. Agardh (Sip_tro) - SOC NC - S\&O SC

Struveopsis siamensis (Egerod) P. Silva (Str_sia) - S\&O SC

Ventricaria ventricosa (J. Agardh) Olsen \& J. West (Ven_ven) - S\&O NC

Valoniaceae

Valoniopsis pachynema (G. Martens) Børgesen (Val_pac) - MAS EC - MAS WC - S\&O NC

Dasycladales

Dasycladaceae

Neomeris van-bosseae Howe (Neo_van) - SOC NC - S\&O SC

Polyphysaceae

Acetabularia sp. (Ace_spe) - SOC NC - S\&O NC - S\&O SC 
Appendix I continued

Ulvales

Ulvaceae

Enteromorpha sp. (Ent_spe) - MAS SG - SOC NC

Ulva sp. (Ulv_spe) - MAS WC - MAS SG - SOC NC - S\&O NC - S\&O SC

\section{Magnoliophyta}

Alismatales

Cymodoceaceae

Halodule uninervis (Forsskål) Ascherson (Hal_uni) - MAS SG - SOC NC - SOC SG

Syringodium isoetifolium (Ascherson) Dandy (Syr_iso) - MAS SG

Thalassodendron ciliatum (Forsskål) den Hartog (Tha_cil) - MAS SG - SOC NC - S\&O NC

Hydrocharitaceae

Halophila decipiens Ostenfeld (Hal_dec) - S\&O SC

Halophila ovalis (R. Brown) Hooker (Hal_ova) - MAS SG - SOC SG

Thalassia hemprichii (Ehrenberg) Ascherson (Tha_hem) - SOC SG 